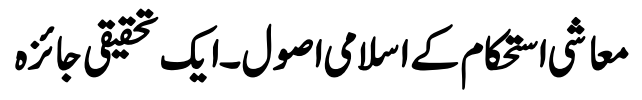

\title{
Islamic Principles of Economic Stability \\ (A Research Review)
}

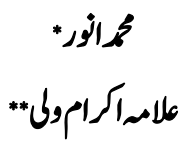

\begin{abstract}
Economic stability is very important in the human life and plays important role in making the life easy and comfortable. Therefore every person in the society wants his economy to be stable.
\end{abstract}

Islam wants stability of economic. Islamic economics is a complete system which provides the basic rules and principles of economic stability which are must for the economy to grow and be stable.

Islam provides a framework and guide lines for mankind, by which human beings should conduct their economic affairs to maintain the economy stable.

This article attempts to analyze Islamic Principles of Economic stability. This study employed a critical and comparative research methodology for analyzing the basic Islamic principles which plays significant role in the economic stability of a person and society. This study will contribute in the field of Islamic Economics and will be beneficial for researchers and scholars of Islamic economic and Islamic banking.

Key words: Islamic Economics, Islamic Banking, Economic Stability, Stable Economy.

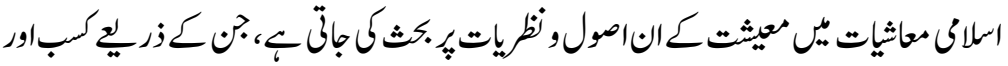

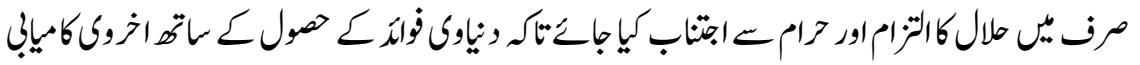

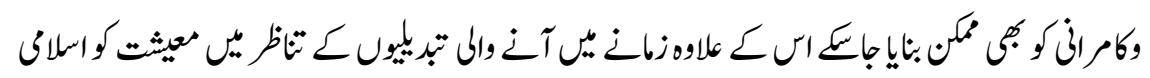

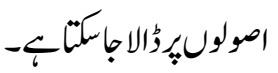

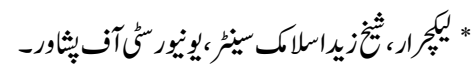

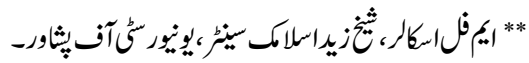


جزرك-جون2020

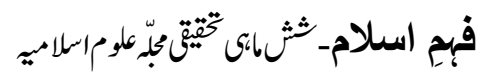

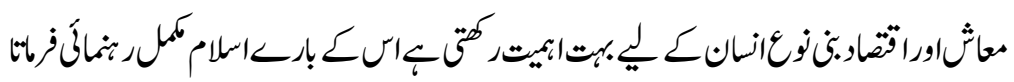

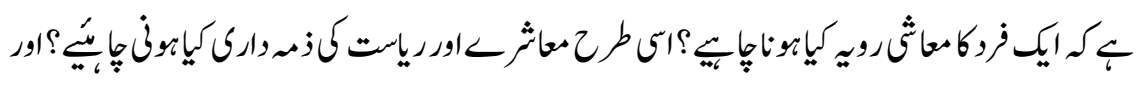

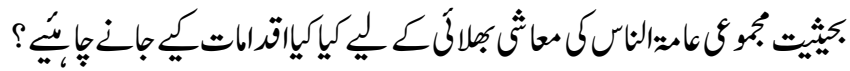

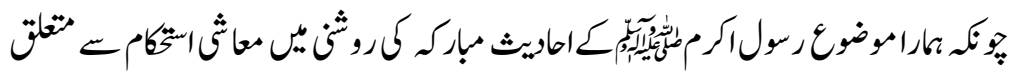

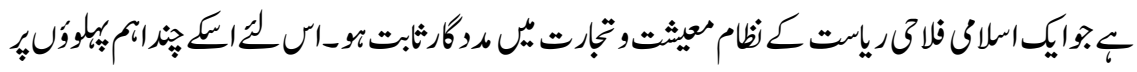

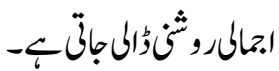

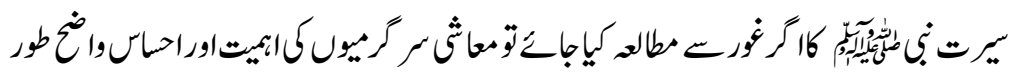

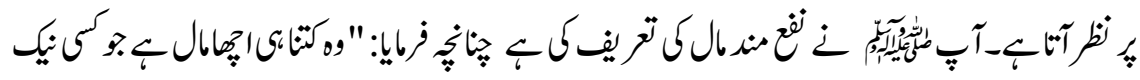

انسانك بإنو-1"

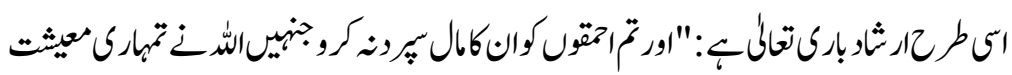

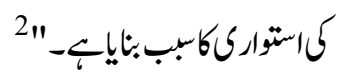

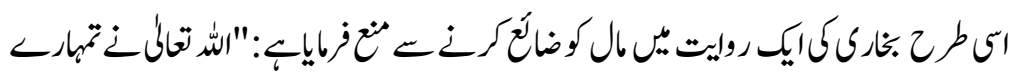

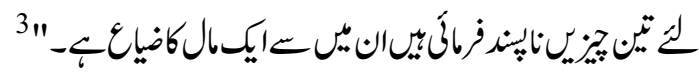

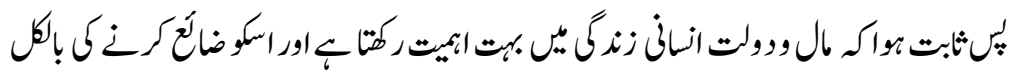

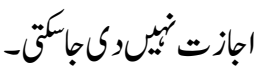

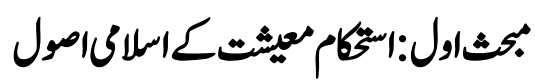

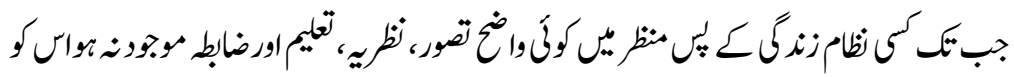

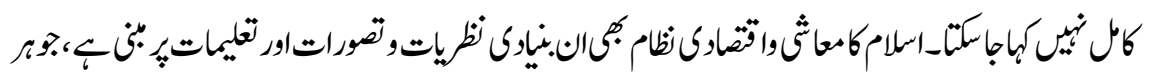

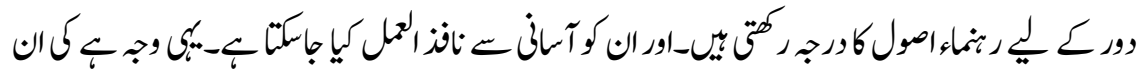

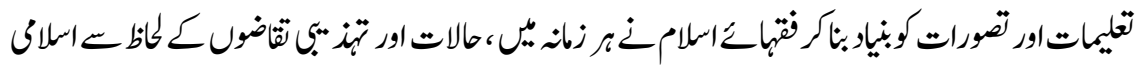

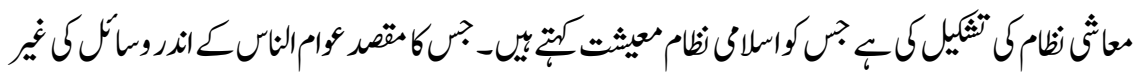

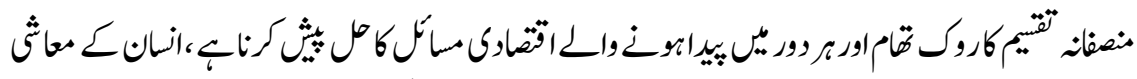

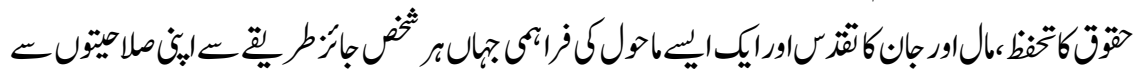

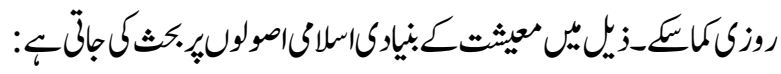

160 


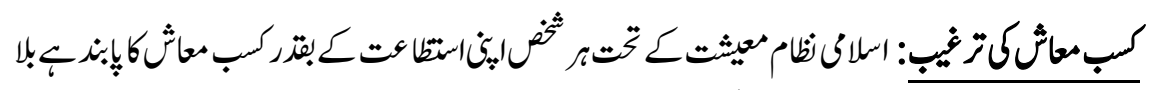

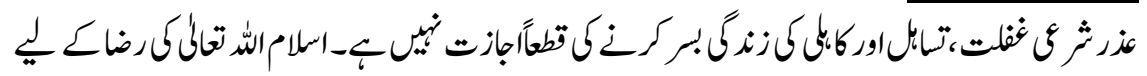

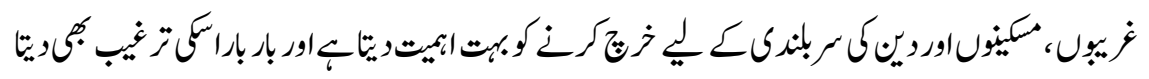

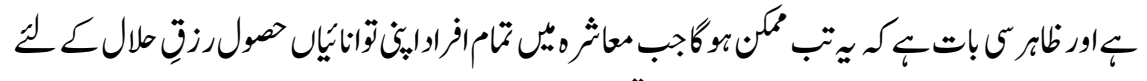

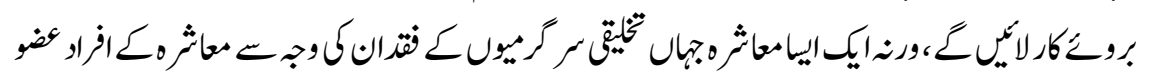

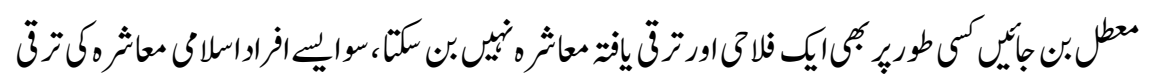

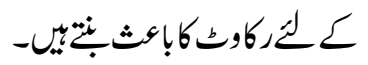

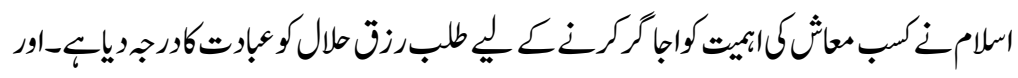

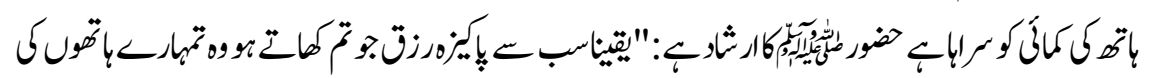

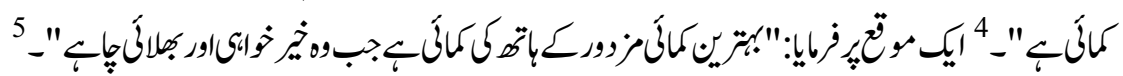

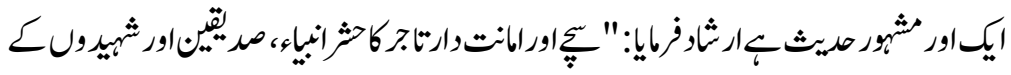

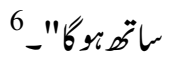

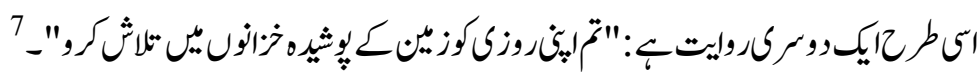

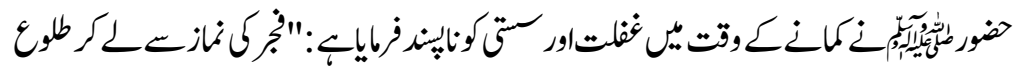

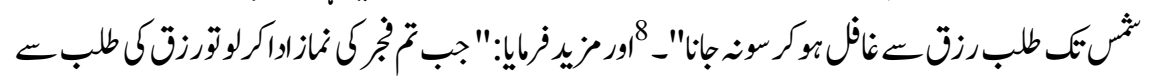

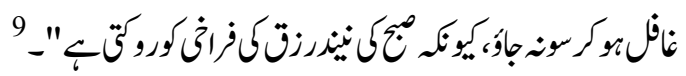

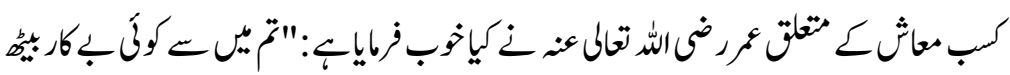

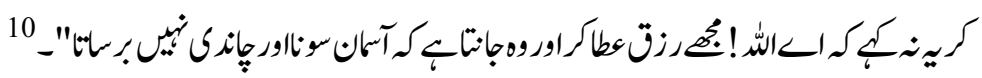

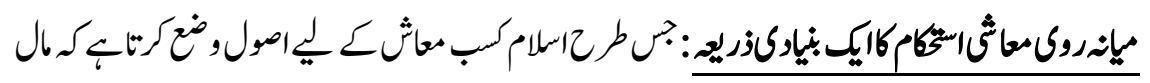

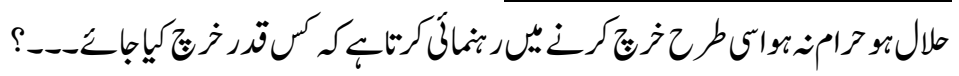

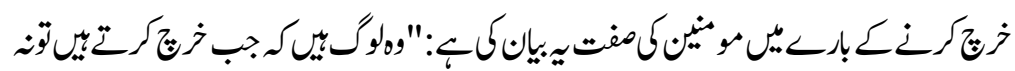

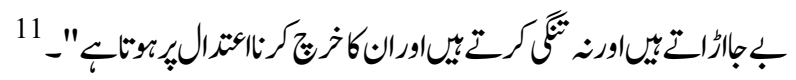

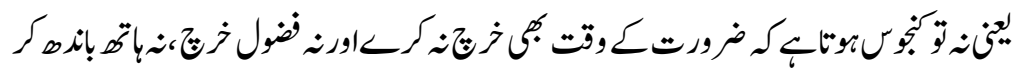

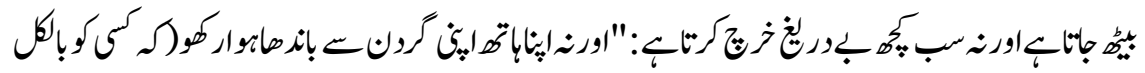

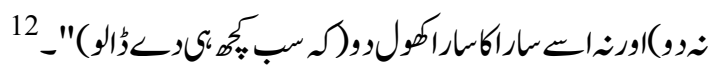




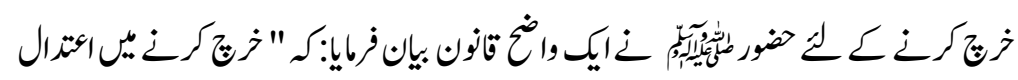

$$
\text { نصف مويثتبك" } 13
$$

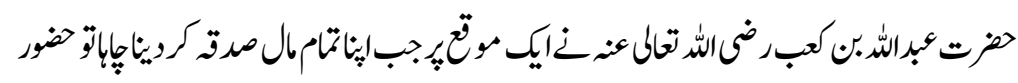

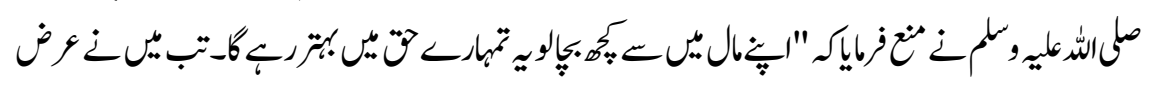

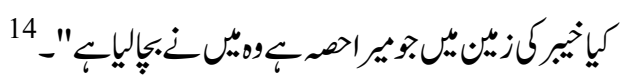

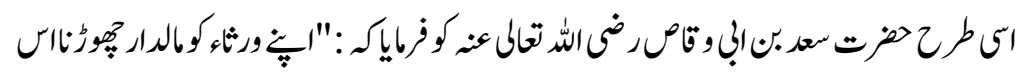

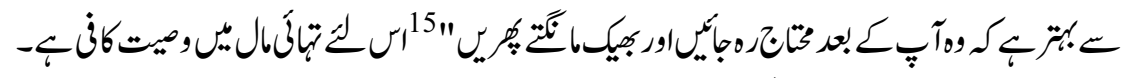

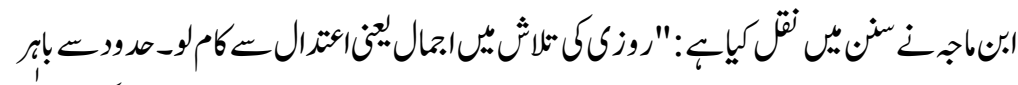

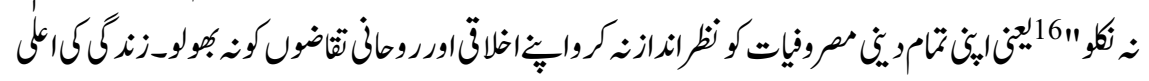

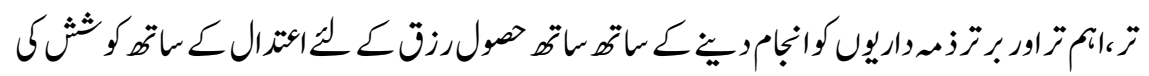

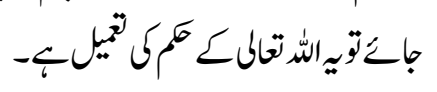

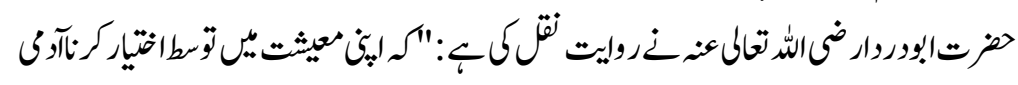

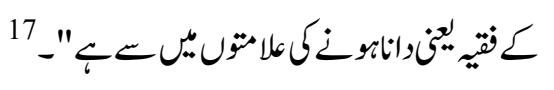

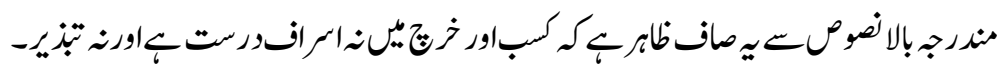

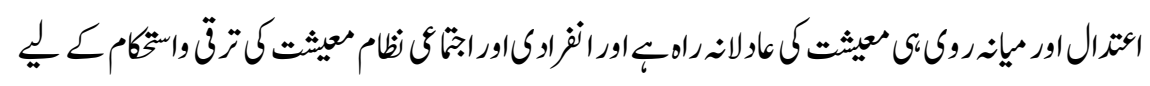
ناكزير

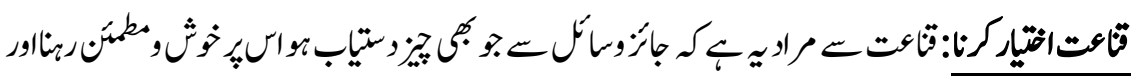

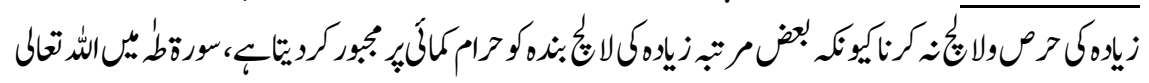

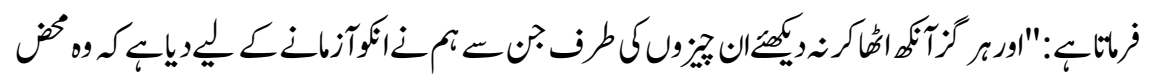
نيوكننك كمرونَ 18

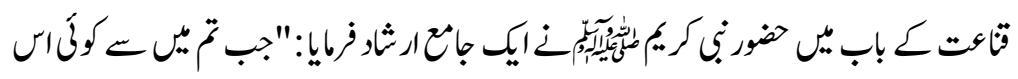

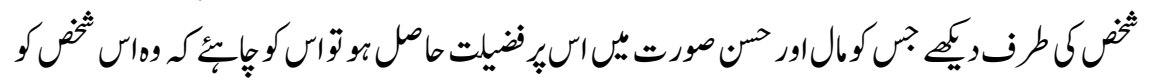

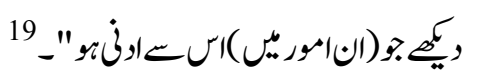


جزرك-جون2020

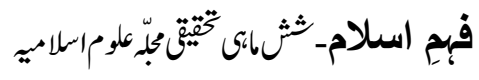

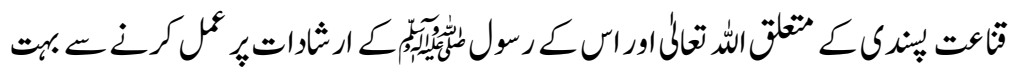

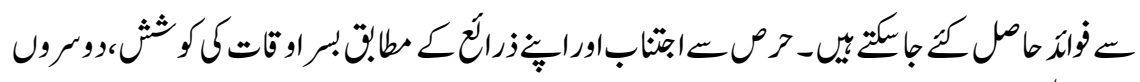

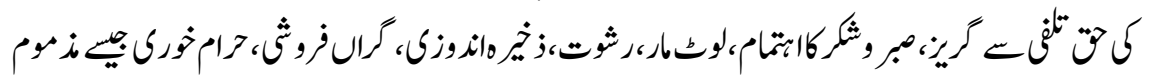

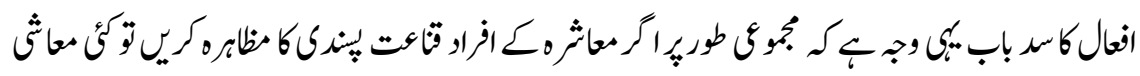

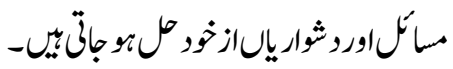

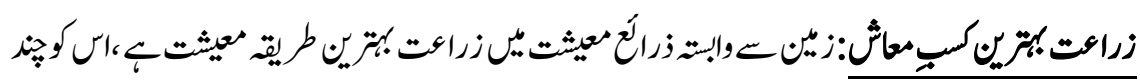

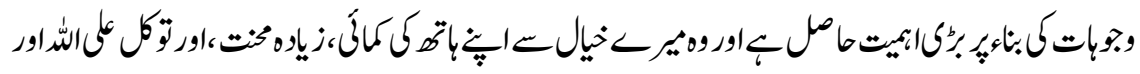

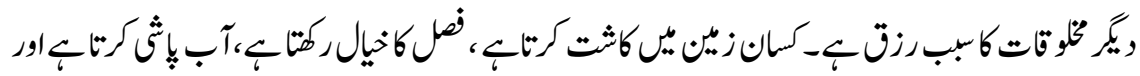

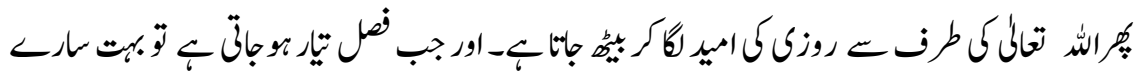

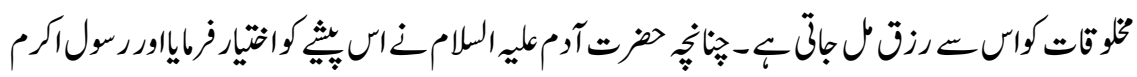

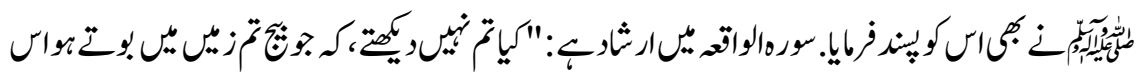

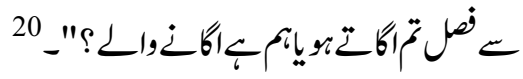

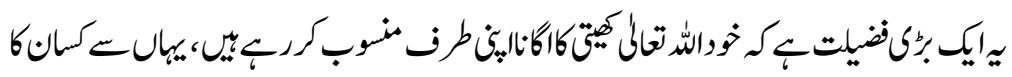

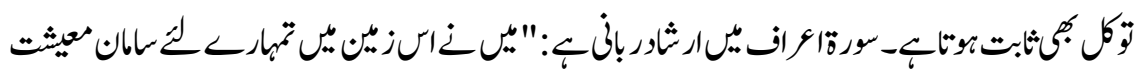
21 بنايإ

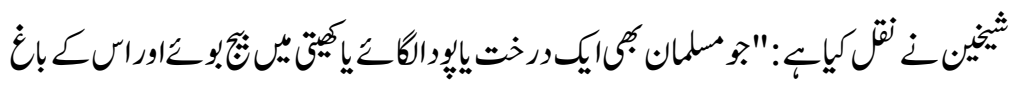

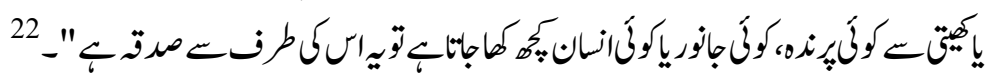

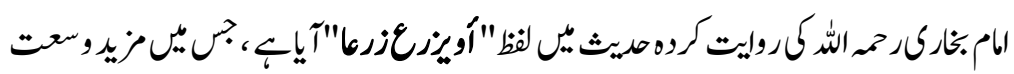

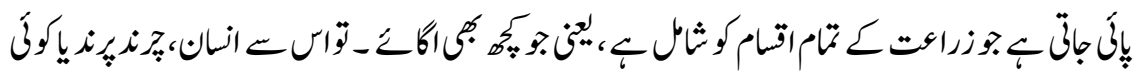

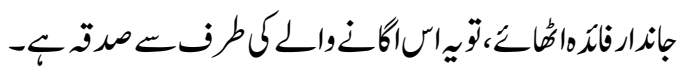

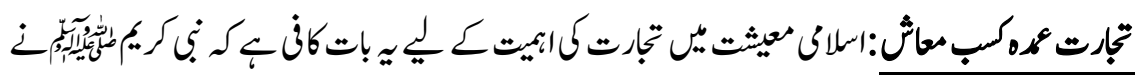

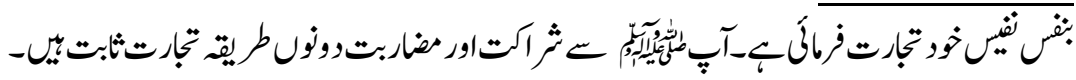

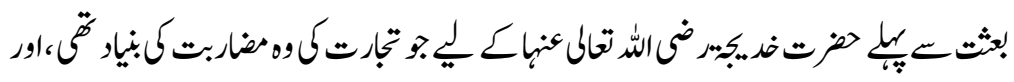

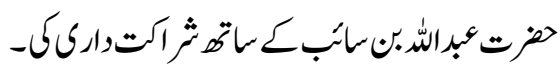

163 


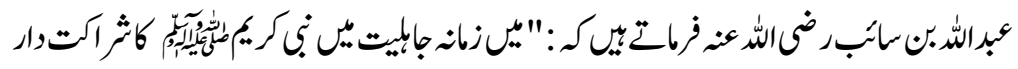

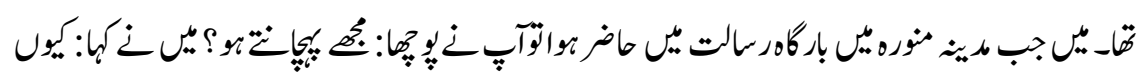

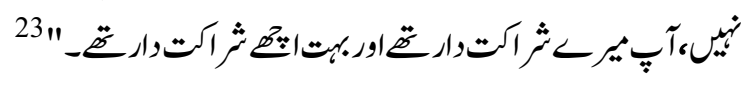

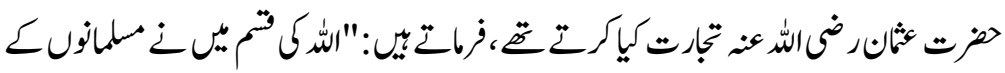

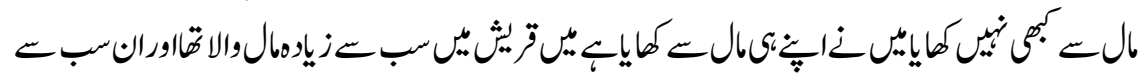

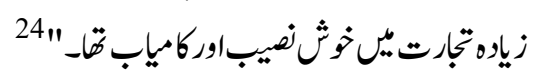

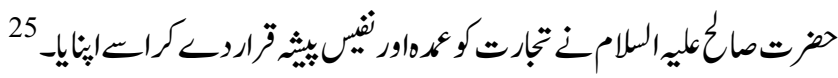

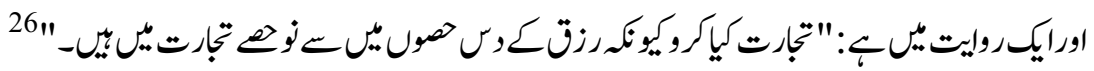

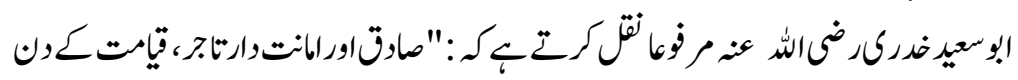

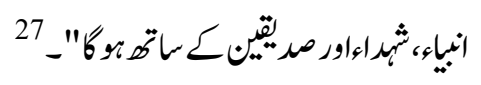

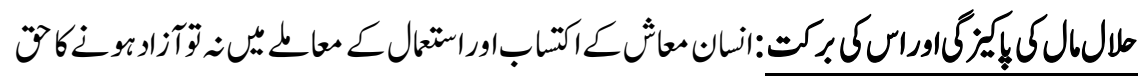

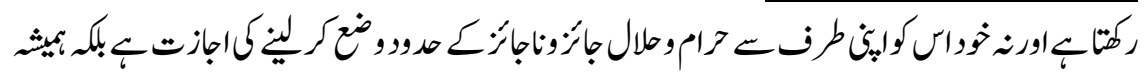

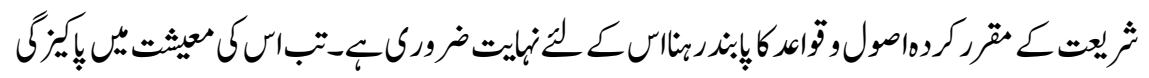

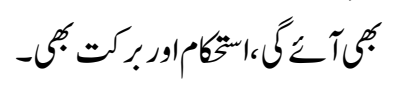

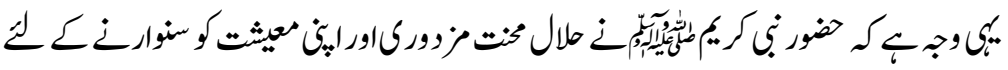

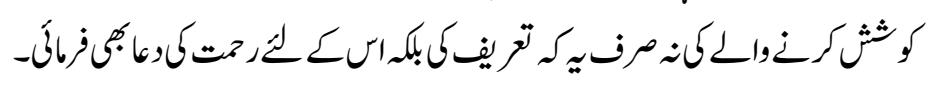

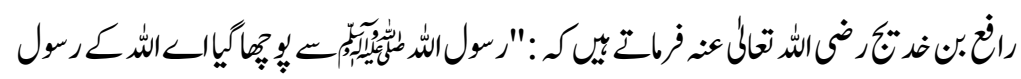

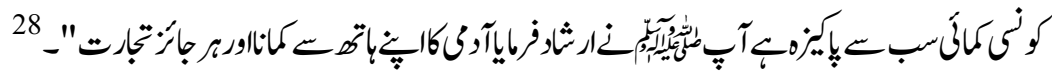

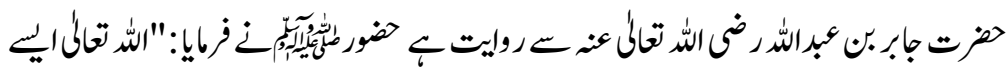

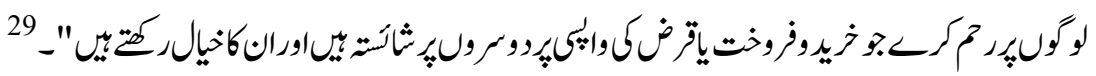

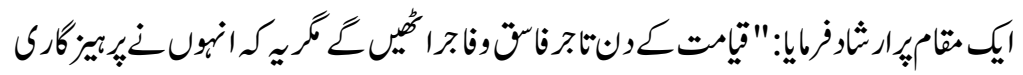

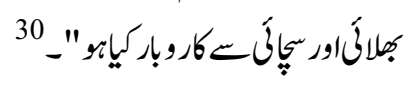

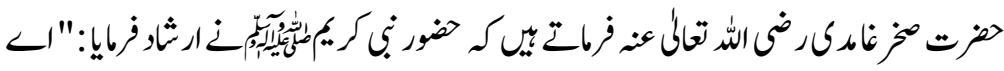

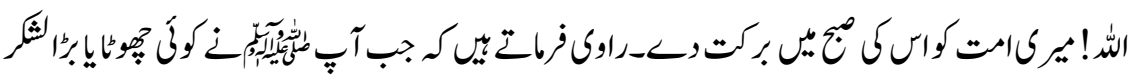




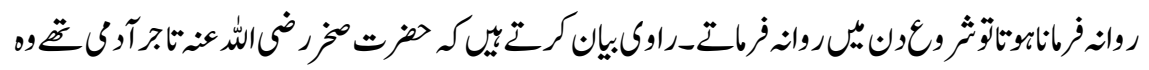

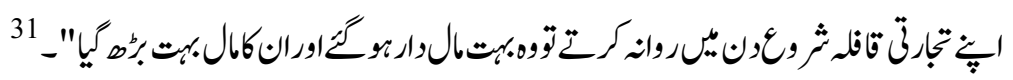

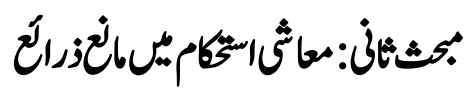

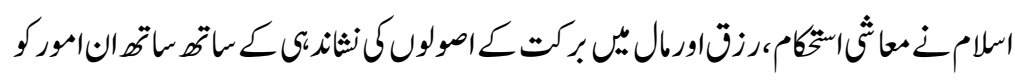

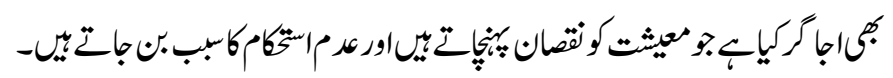

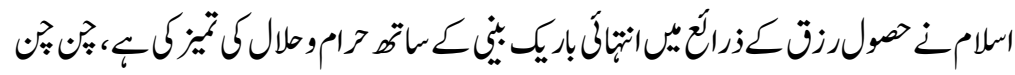

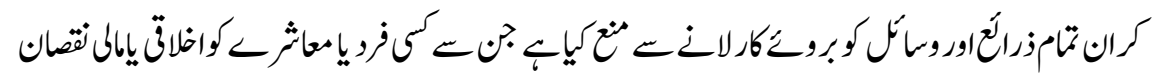

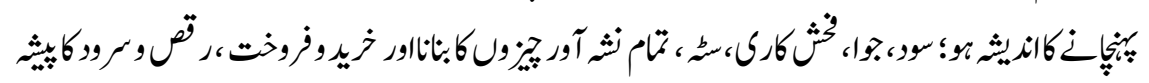

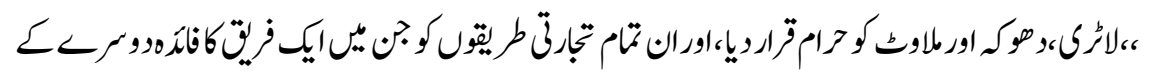

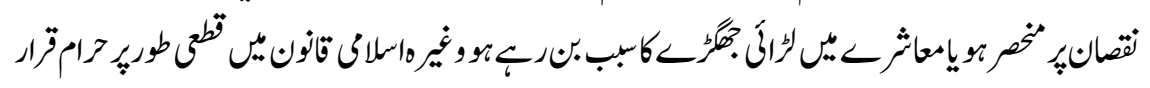

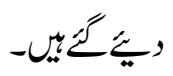

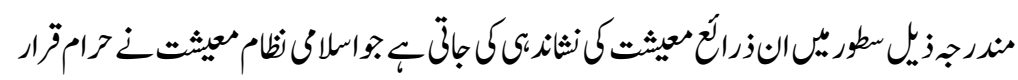

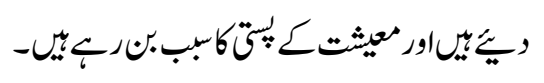

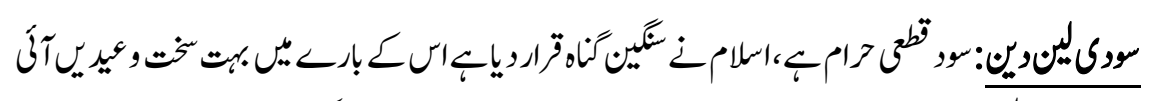

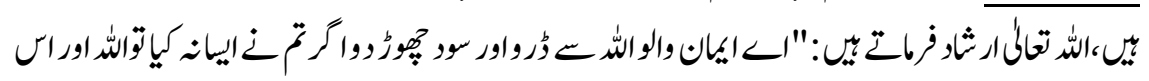

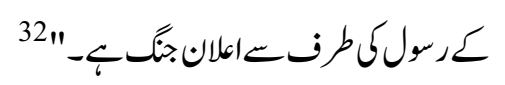

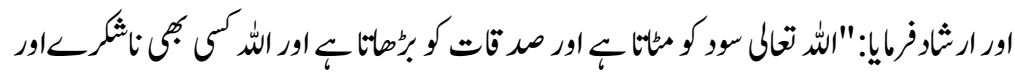

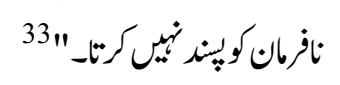

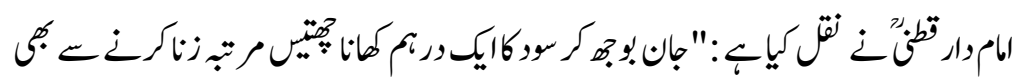

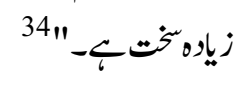

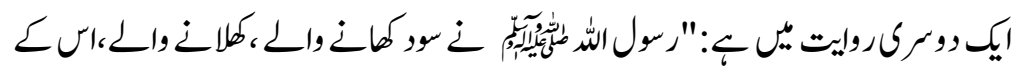

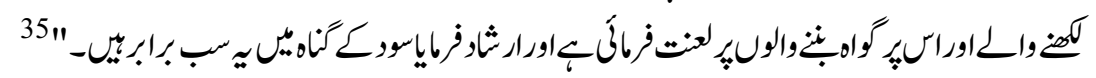

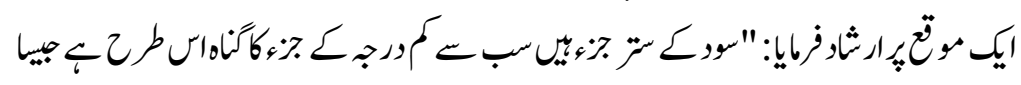

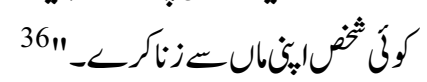


جزرك-:جون2020

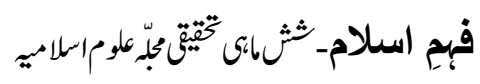

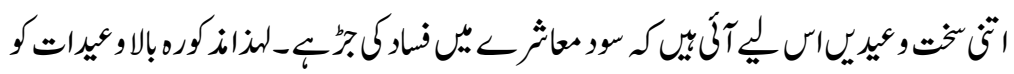

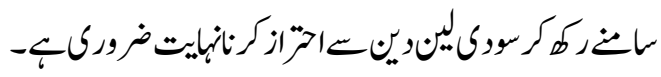

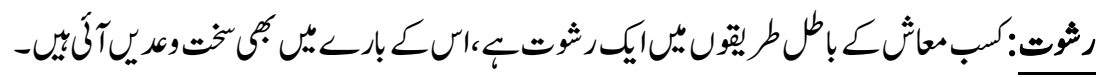

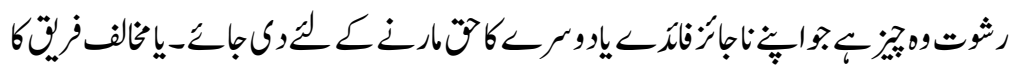

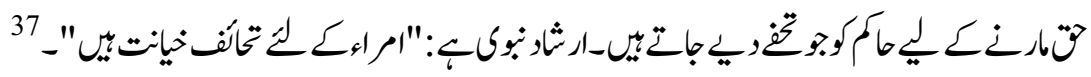

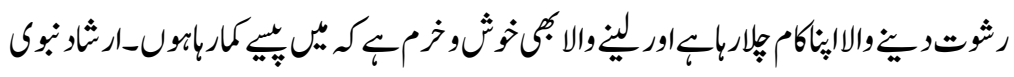

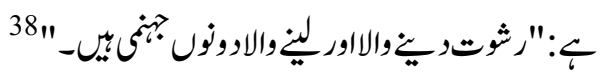

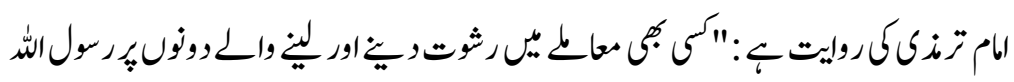

$39 "$

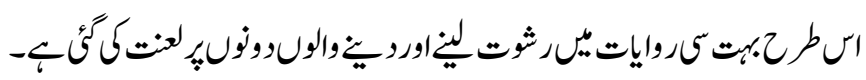

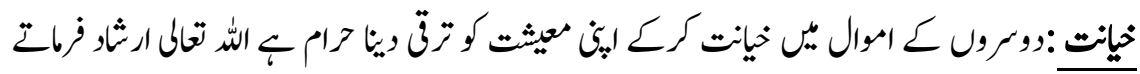

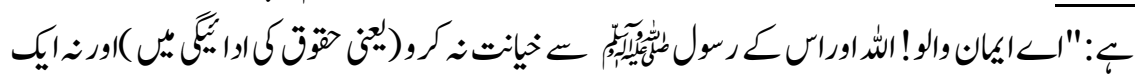

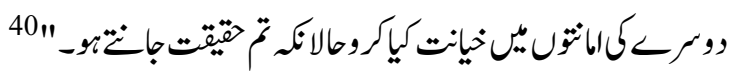

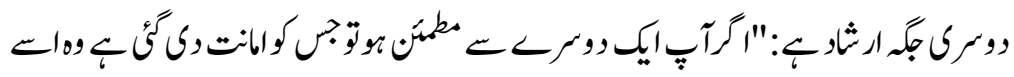

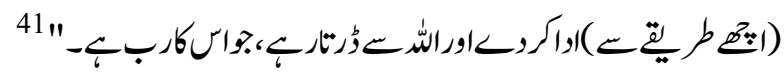

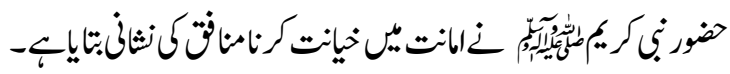

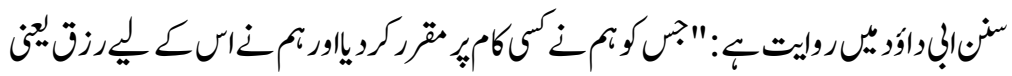

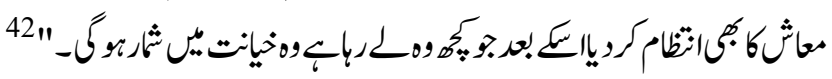

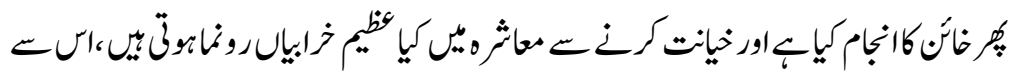

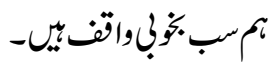

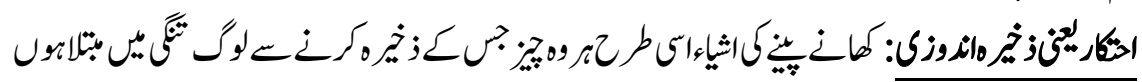

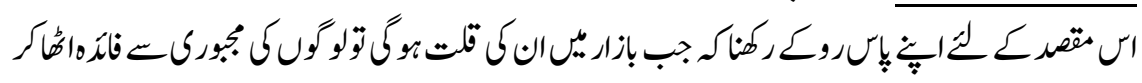

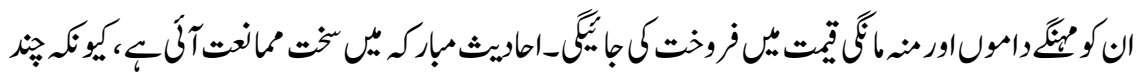

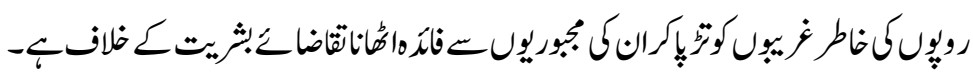

166 
جزرك-:جون2020

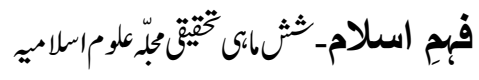

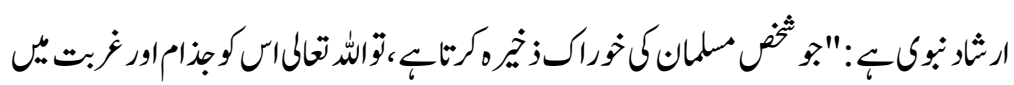

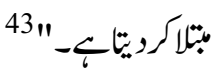

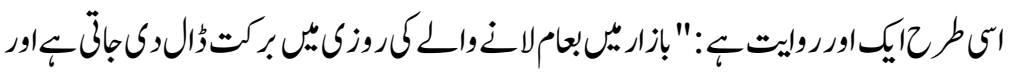

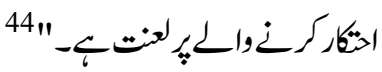

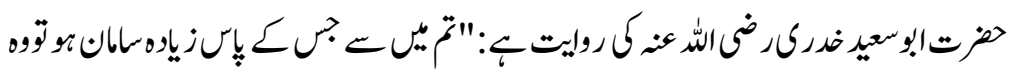

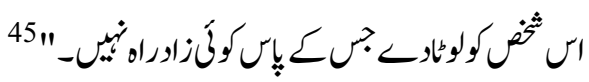

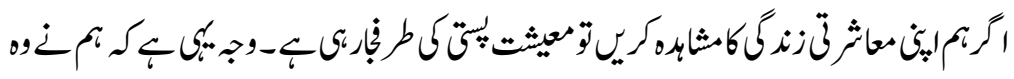

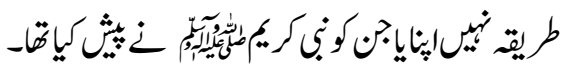

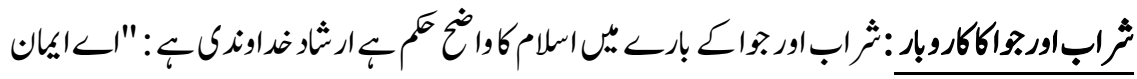

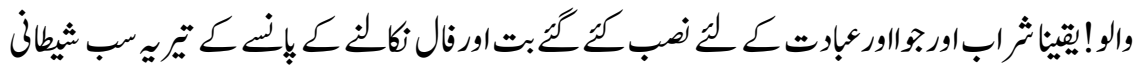

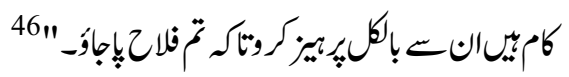

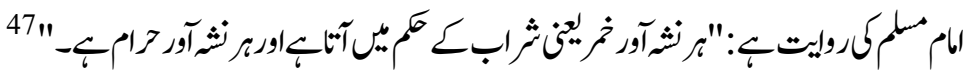

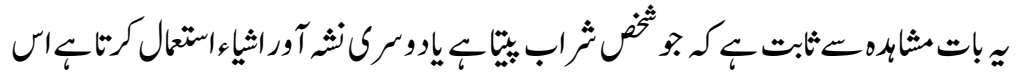

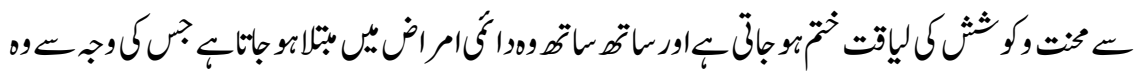

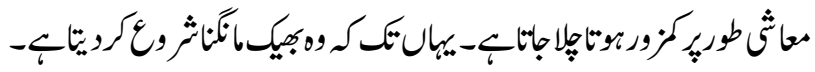

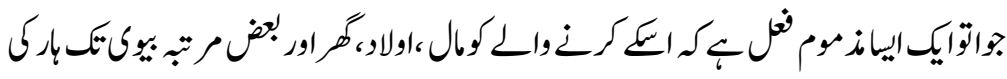

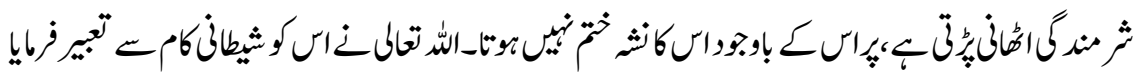

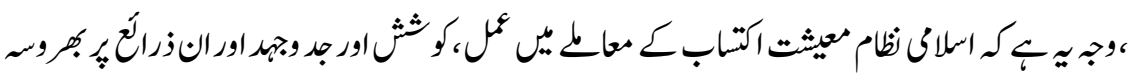

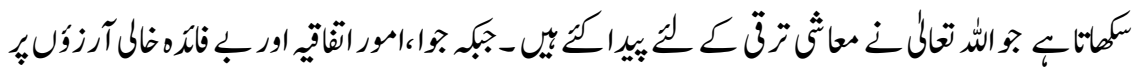

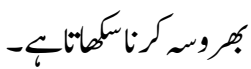

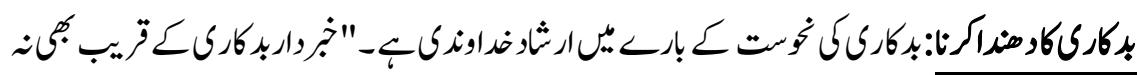

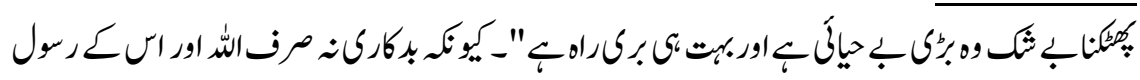

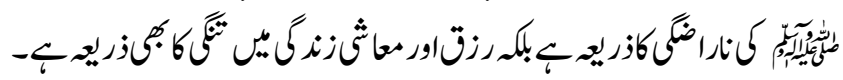

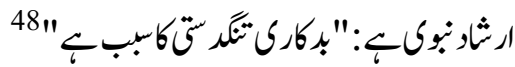

167 


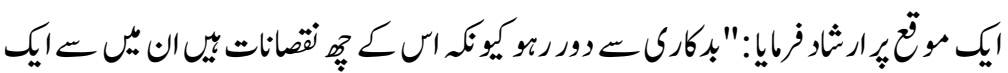

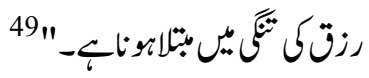

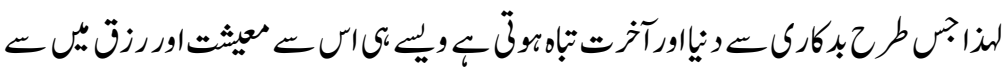

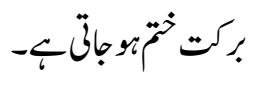

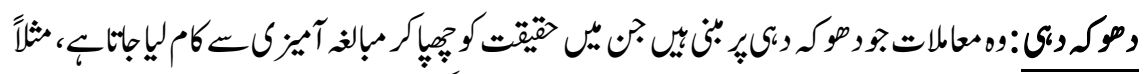

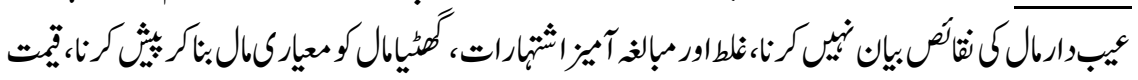

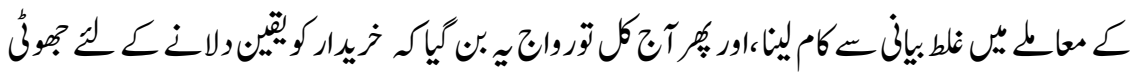

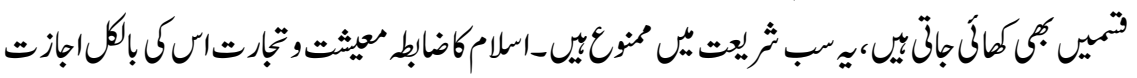

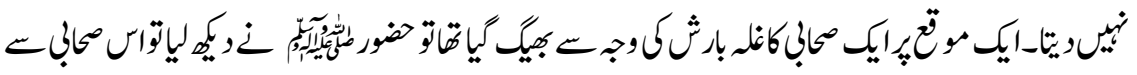

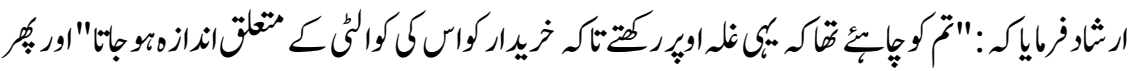

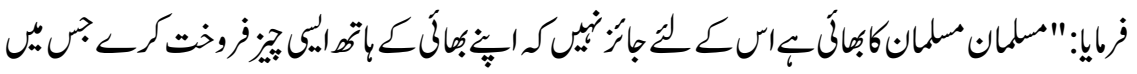
عيب،واوراس عيباور نتص كبيان: كركــ"

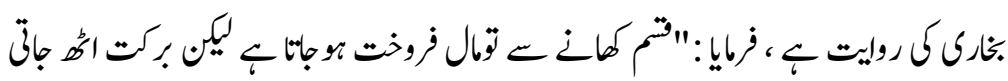

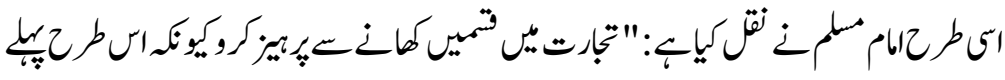

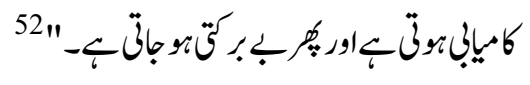

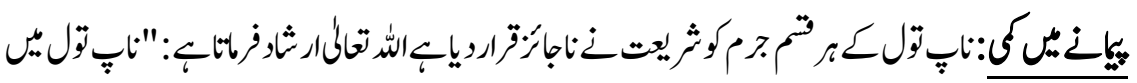

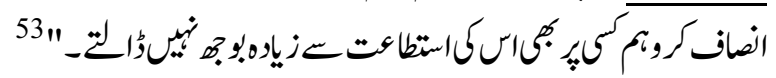

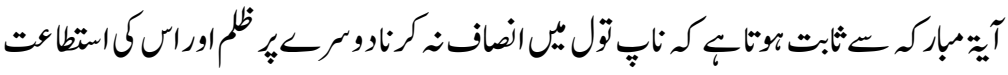

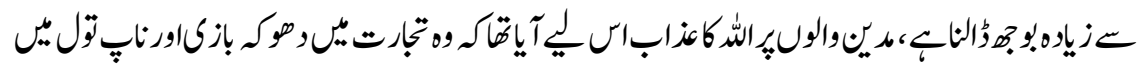

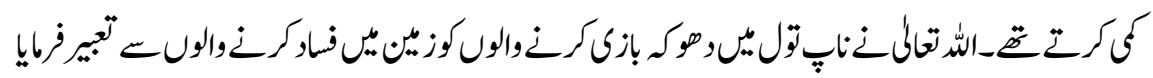




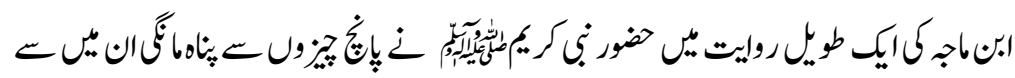

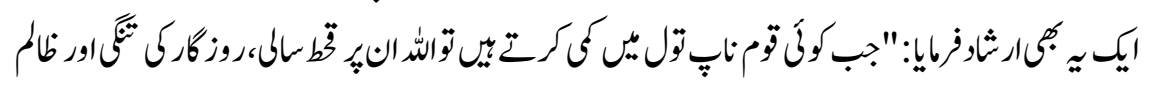

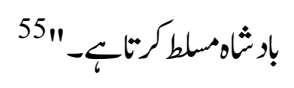

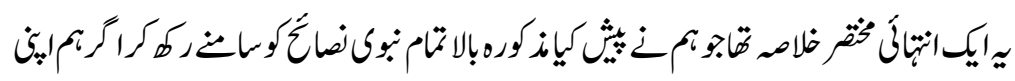

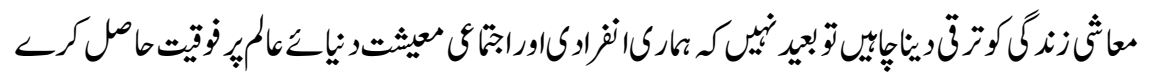

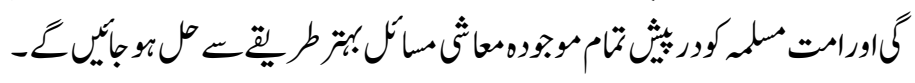

\section{ناصمونتاعُكث}

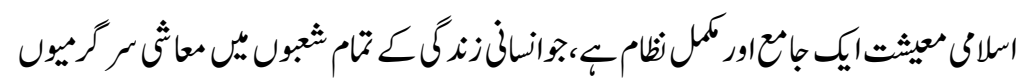

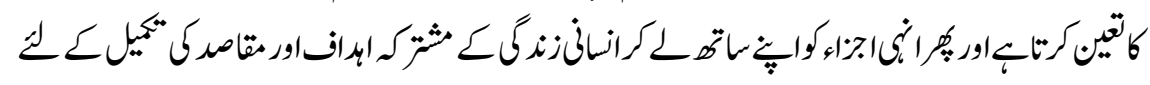

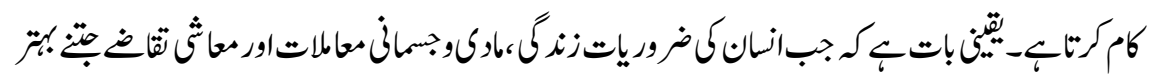

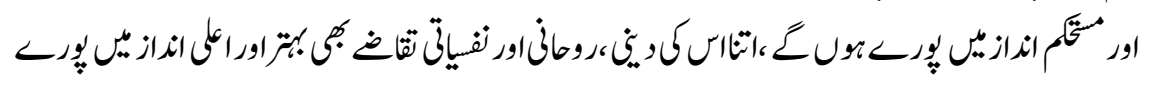
مبع

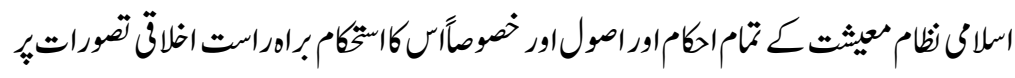

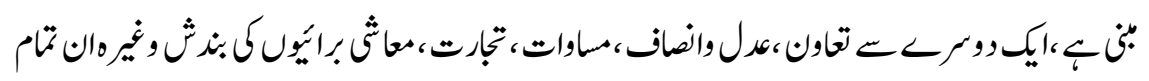

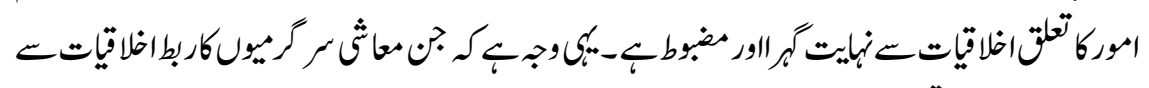

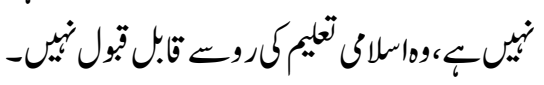

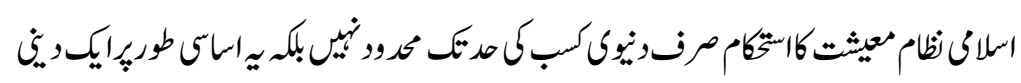

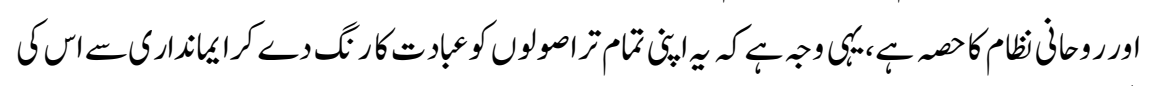

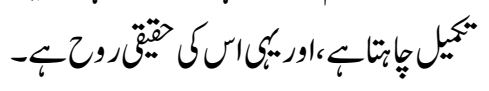

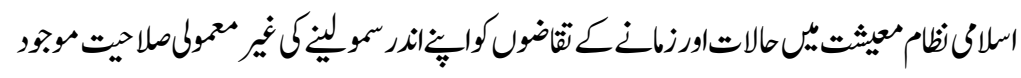

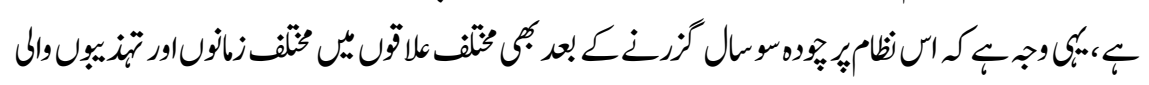

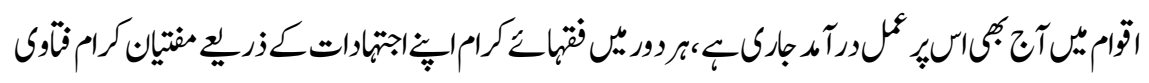

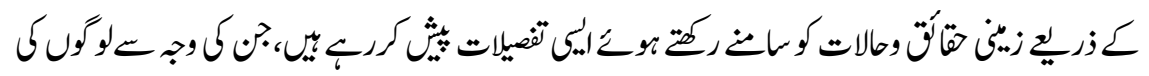

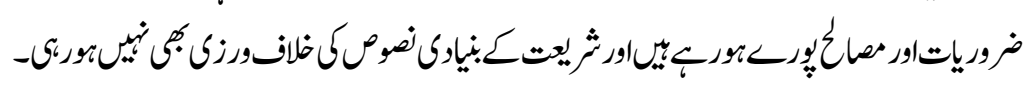




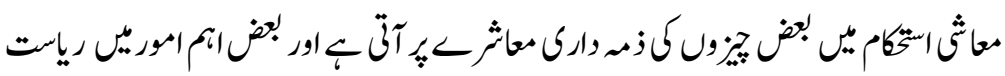

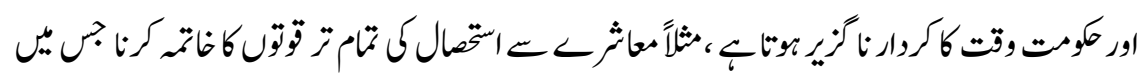

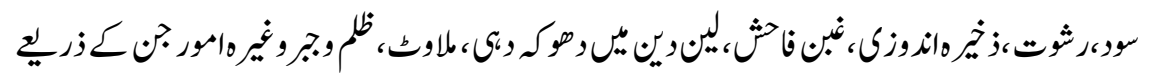

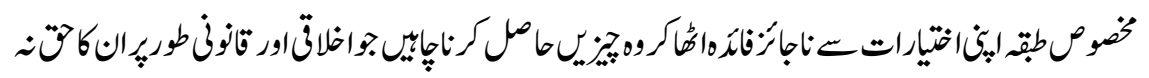
هو

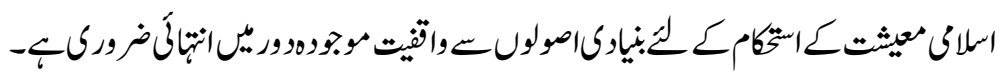

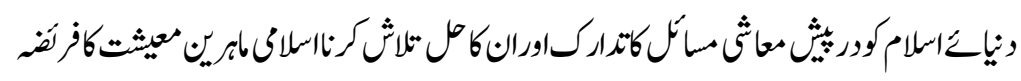

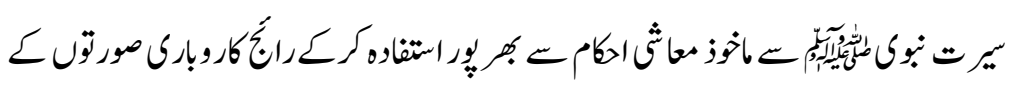

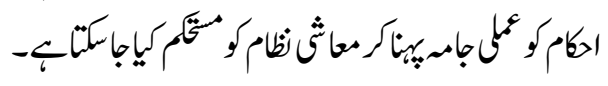

هالدجات

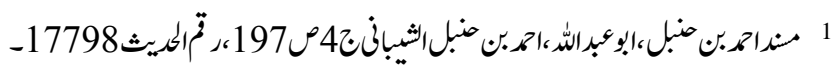
2 سورة/الناء:5

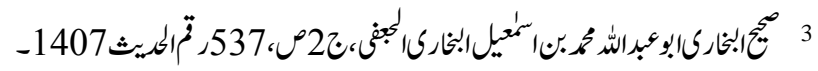

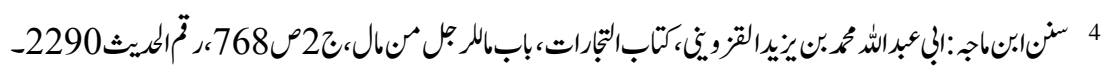

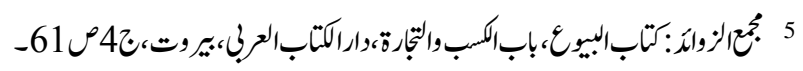

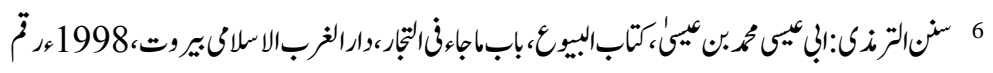
الحيثيث1209-120

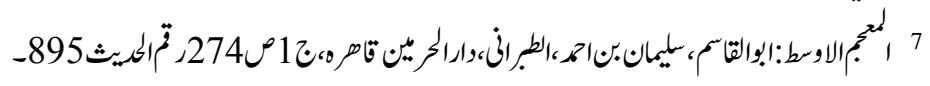

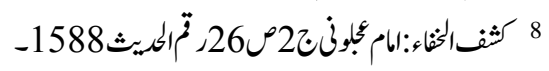

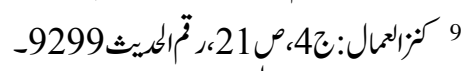

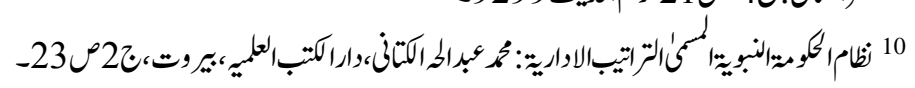

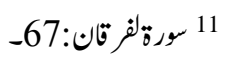
12 بورة الا أراء:29-

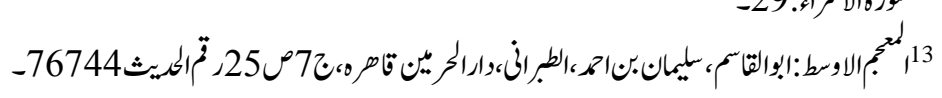

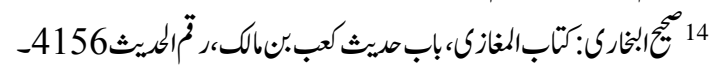




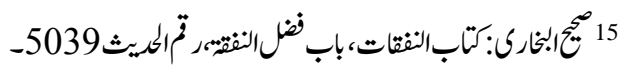

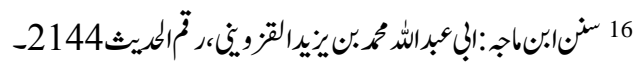

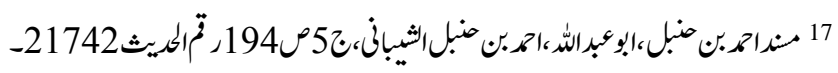

$$
\begin{aligned}
& \text { 18 }
\end{aligned}
$$

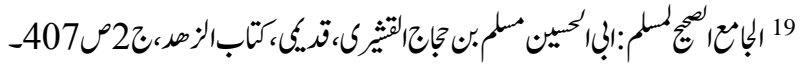

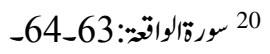

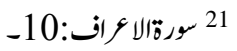

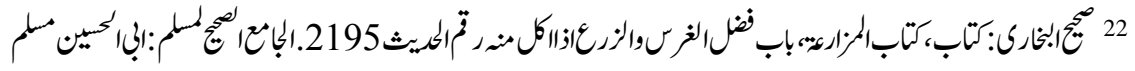

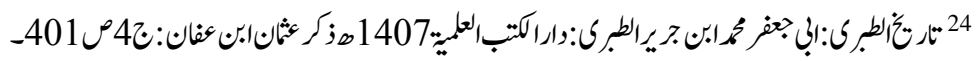

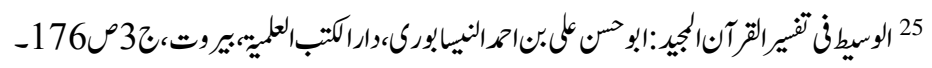

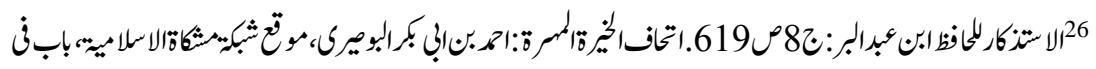
التّارة،2750 275-

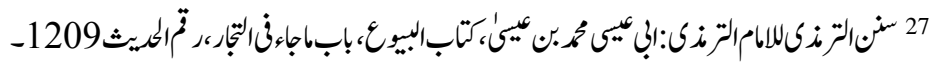

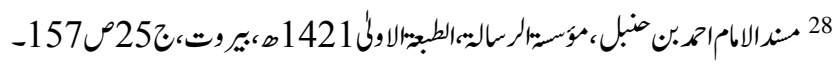

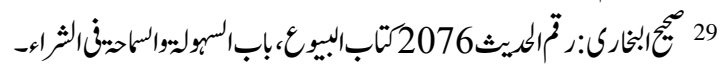

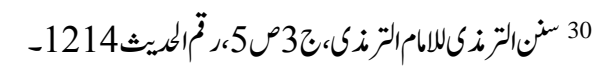

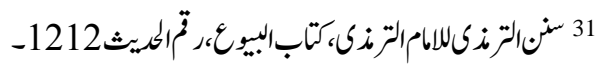
32 سورة|ابقرة:279/278ــ 33

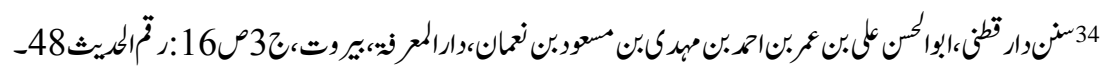

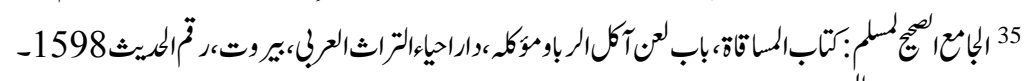

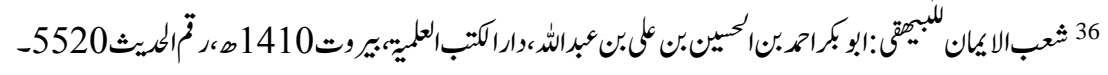

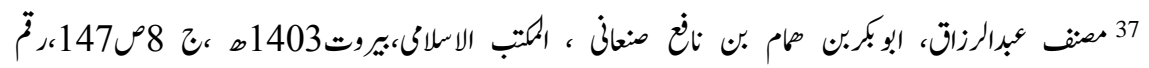
الحيث14665-

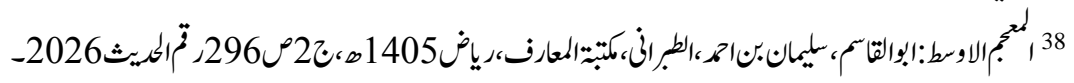




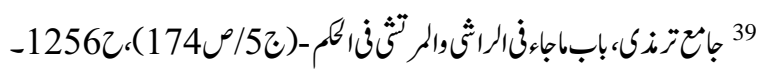

40 بورة/النفال:2741 بورة/الترة:283-

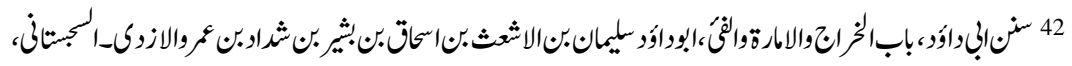

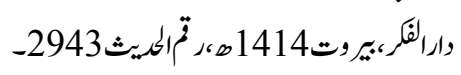

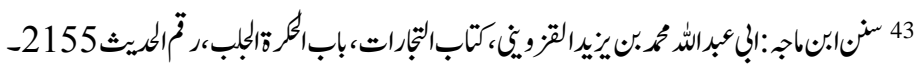

$$
\text { 44 } 44
$$

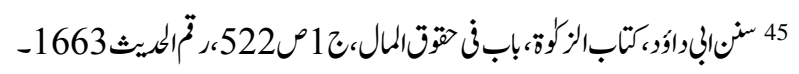

$$
46 \text { بورة المانَة: } 40
$$

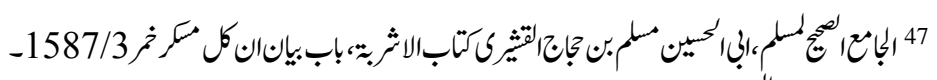

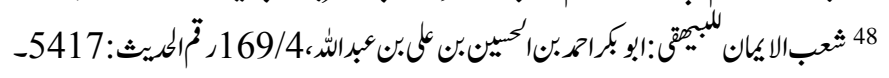

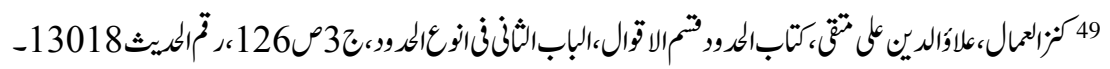

$$
\begin{aligned}
& 50
\end{aligned}
$$

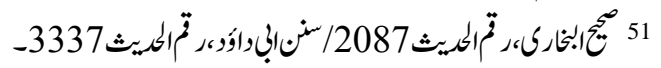

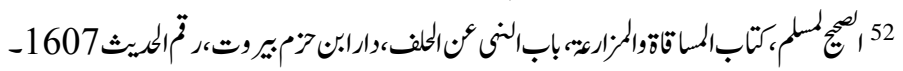

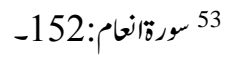

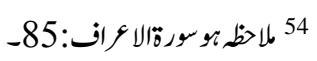

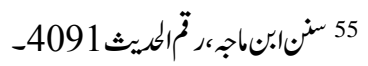

